\title{
THE SECRETARY'S VOICE
}

Thomas Unger

CARIM - School for Cardiovascular Research, Maastricht University, Maastricht, The Netherlands

DOI: $10.30824 / 2006-4$

An exciting and highly productive period of our Society is approaching the end. In October, a new president will take over and with him a new Executive Council.

\section{Time to look back and to review the Society's achievements of the last two years under the presidentship of Alta Schutte (2018-2020).}

\section{There was of course the ISH congress} in Beijing still under the presidentship of Neil Poulter (2016-2018) which was held together with the Chinese Hypertension League $(\mathrm{CHL})$ and the Asian Pacific Society of Hypertension (APSH) in September 2018 with up to 3.000 participants. Scientifically, this meeting was a great success, and we all enjoyed the warm hospitality of our Chinese friends.

Then the tremendous activities of the May Measurement Month (MMM) led by Neil Poulter over the last three years with more than one hundred countries involved, more than two million of individuals having their blood pressure measured, and almost one million untreated or inadequately treated hypertensives detected. Beyond this, with a number of publications in high-ranking journals, MMM exerts an impact on the global awareness of hypertension as the most important cardiovascular risk factor and, in particular, features ISH as the only globally acting hypertension society. MMM takes care of a new recognition of the devastating role of high blood pressure, especially in times where hypertension tends to be rather neglected, its research is not

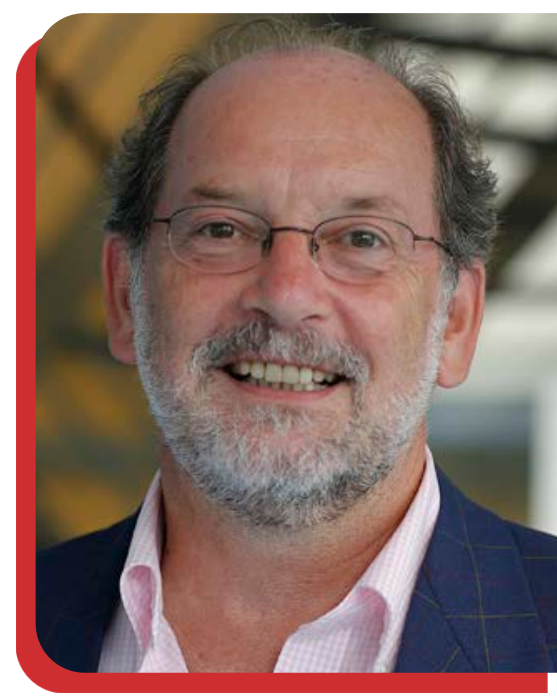

supported to a significant extent any more by funding agencies, academic institutions and the pharmaceutical industry, and where academic Departments of Hypertension dwindle.

Under these unfavourable conditions, institutions like MMM are more important than ever to maintain and even refresh the public awareness of the "silent killer number one". And, as it says on the ISH homepage, the significance of MMM can also be seen as "to collect the scientific evidence needed to help influence global health policy and make BP screening more widely available around the world".

MMM has done a tremendous job in this respect. Due to the current situation under the yoke of the Corona Pandemic, the MMM activities have been postponed for the year 2020 and will hopefully be resumed in the next year as one of the ISH flagships.

Covid-19 also prevented the planned congress of ISH together with the European Society of Hypertension (ESH) and the British and Irish Hypertension Society (BIHS) in Glasgow, UK, due to take place at the end of May 2020. The joint congress has been postponed to April 11-14, 2021 at the same venue. The Society will make sure that information about all related changes and plans including new abstract submission etc. are widely communicated in due time.

The Society will not present any awards this year as the awards ceremonies have also been postponed to the 2021 congress. A new call for award nominations will be circulated in December 2020. 
The biennial general meeting of the Society, which should have taken place during the Glasgow congress, has been postponed to October 2020 as a virtual meeting so that the current president and executive council will finish their two-year terms correctly in the autumn according to the Society's constitution. Members will be invited to an online General Meeting in October which will have normal reporting including finances and general activities of the council.

Speaking of finances, these are in good order under the supervision of the current treasurer, Markus Schlaich, thanks to his continuous, intensive efforts. The ISH Bejing meeting, despite being held under difficult financial conditions, has made a surplus, and the cancellation of this year's congress will save costs but these will of course be incurred again in April 2021 when the congress takes place.

ISH has launched a new fellowship "International Society of Hypertension Fellow (ISHF)" similar to the AHA and ESC fellowships to "recognise and honour members of the Society who have distinguished themselves through excellence in clinical practice or research in the field of Hypertension". So far, more than 100 applications have been received. Once the applications have been approved by the Executive Committee, applicants will be honoured in April 2021 at the ISH congress. A second call for nominations will be circulated before the congress.
Finally, one of the major tasks of the Society in the last two years was the creation of new ISH Hypertension Guidelines. These have been published recently in two journals, Journal of Hypertension and Hypertension, concomitantly on May 6, 2020, and printed in the respective June 2020 issues. Links to these and other means of the Guideline dissemination can be found on the ISH homepage under www.ish-world.com. The new ISH Guidelines are covered extensively in the present issue of Hypertension News.

At this point I would like to express my deep gratitude to Alta Schutte, our current president, and to the members of the Executive Committee and Council. It has been a pleasure to work with you as the Society's Secretary and Chair of the Hypertension Guidelines Committee. I highly appreciate the friendly and trustful atmosphere created by the president, allowing among others, for vivid, sometimes controversial, but always constructive discussions. Major achievements like the production of new Guidelines can only be performed under such friendly skies, and I sincerely hope they will continue in the future for the benefit of our Society and its global mission.

Thomas Unger - thomas.unger@maastrichtuniversity.nl

\section{ISH Global Practice Guidelines Resources}

All information and resources related to the 2020 ISH Global Hypertension

Practice Guidelines are available on the ISH website including:

- Publication in Hypertension

- Publication in publication in J Hypertension

- Slide deck

- Webinar in English and Chinese 